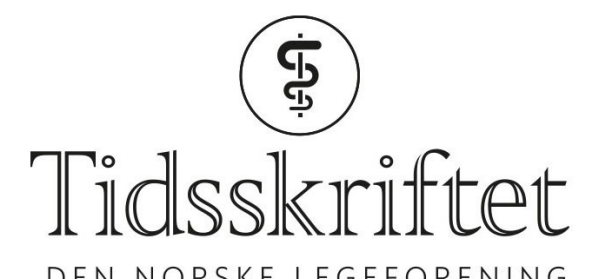

DEN NORSKE LEGEFORENING

\title{
Praktisk håndtering av hodepine
}

KLINISK OVERSIKT

\section{ANNE HEGE AAMODT}

E-post:a.h.aamodt@medisin.uio.no

Nevrologisk avdeling

Oslo universitetssykehus

Anne Hege Aamodt er ph.d. og overlege ved Nevrologisk avdeling, Oslo universitetssykehus. Hun er leder i Norsk nevrologisk forening.

Forfatteren har fylt ut ICMJE-skjemaet og oppgir følgende interessekonflikter: Hun har mottatt foredragshonorar fra Allergan og Novartis.

\section{MARTE HELENE BJØRK}

Nevrologisk avdeling

Haukeland universitetssykehus

og

Klinisk institutt 1

Universitetet i Bergen

Marte Helene Bjørk er ph.d., konstituert overlege ved Nevrologisk avdeling, Haukeland universitetssykehus, og førsteamanuensis ved Klinisk institutt 1, Universitetet i Bergen. Forfatteren har fylt ut ICMJE-skjemaet og oppgir følgende interessekonflikter: Hun har mottatt honorar fra Allergan og honorarer og forskningsstøtte fra Novartis.

\section{KARL BJØRNAR ALSTADHAUG}

Nevrologisk avdeling Nordlandssykehuset, Bodø

og

Det helsevitenskapelige fakultet

Universitetet i Troms $\varnothing$ - Norges arktiske universitet

Karl Bjørnar Alstadhaug er spesialist i nevrologi, overlege ved Nevrologisk avdeling, Nordlandssykehuset i Bod $\emptyset$, og professor ved Universitetet i Troms $\emptyset$.

Forfatteren har fylt ut ICMJE-skjemaet og oppgir følgende interessekonflikter: Han har mottatt honorar fra Bayer, Biogen, Novartis og Roche.

\section{GUTTORM ELDØEN}

Nevrologisk avdeling

Molde sjukehus

Guttorm Eldøen er spesialist i nevrologi og i øre-nese-halssykdommer og overlege ved Nevrologisk avdeling, Molde sjukehus.

Forfatteren har fylt ut ICMJE-skjemaet og oppgir ingen interessekonflikter.

\section{AUD NOME DUELAND}

Sandvika Nevrosenter

Aud Nome Dueland er dr.med., spesialist i nevrologi og avtalespesialist ved Sandvika Nevrosenter. Forfatteren har fylt ut ICMJE-skjemaet og oppgir følgende interessekonflikter: Hun har mottatt honorar fra Allergan, Apotek 1 og Novartis samt reisestøtte fra Teva. 
TINE POOLE

Volvat Hodepinesenter

Volvat Medisinske Senter, Oslo

Tine Poole er allmennlege med spesiell interesse for migrene og andre hodepinesykdommer. Hun er fagansvarlig lege ved Volvat Hodepinesenter ved Volvat Medisinske Senter i Oslo. Hun var initiativtaker til etablering av brukerorganisasjonen Hodepine Norge i 2017 og styreleder av Norsk Hodepineselskap i 2015-2017.

Forfatteren har fylt ut ICMJE-skjemaet og oppgir følgende interessekonflikter: Hun har mottatt foredragshonorar og sittet i rådgivningsgruppe for Allergan, Astra Zeneca, GSK, MSD, Novartis, Organon, Pfizer og Teva.

\section{KNUT HAGEN}

Nasjonalt kompetansesenter for hodepine

Avdeling for nevrologi og klinisk nevrofysiologi

St. Olavs Hospital

og

Institutt for nevromedisin og bevegelsesvitenskap

NTNU

Knut Hagen er dr.med., spesialist i nevrologi, overlege og professor tilknyttet Nasjonal

kompetansetjeneste for hodepine ved NTNU og St. Olavs hospital.

Forfatteren har fylt ut ICMJE-skjemaet og oppgir følgende interessekonflikt: Han sitter i rådgivningspanel for The Journal of Headache and Pain.

\section{KJERSTI GRØTTA VETVIK}

Nevrologisk avdeling

Akershus universitetssykehus

Kjersti Grøtta Vetvik er ph.d., spesialist i nevrologi og overlege ved Nevroklinikken, Akershus universitetssykehus.

Forfatteren har fylt ut ICMJE-skjemaet og oppgir følgende interessekonflikter: Hun har mottatt honorarer fra Novartis, Roche og Teva.

\section{HILDE KAREN OFTE}

Nevrologisk avdeling

Nordlandssykehuset, Bodø

Hilde Karen Ofte er ph.d., spesialist i nevrologi og overlege ved Nevrologisk avdeling,

Nordlandssykehuset i Bodø. Hun er leder i Norsk Hodepineselskap.

Forfatteren har fylt ut ICMJE-skjemaet og oppgir ingen interessekonflikter.

\section{JULIE SØNNERVIK}

Hodeverket hodepineklinikk, Sandnes

Julie Sønnervik er spesialist i nevrologi og har drevet Hodeverket hodepineklinikk i Sandnes fra 2007. Hun jobber også deltid med rehabilitering.

Forfatteren har fylt ut ICMJE-skjemaet og oppgir ingen interessekonflikter.

\section{ESPEN SAXHAUG KRISTOFFERSEN}

Nevrologisk avdeling

Akershus universitetssykehus

og

Avdeling for allmennmedisin

Institutt for helse og samfunn

Universitetet i Oslo

Espen Saxhaug Kristoffersen er ph.d., lege i spesialisering i nevrologi ved Nevroklinikken, Akershus universitetssykehus, og førsteamanuensis ved Avdeling for allmennmedisin, Universitetet i Oslo. Forfatteren har fylt ut ICMJE-skjemaet og oppgir ingen interessekonflikter.

\section{BENDIK SLAGSVOLD WINSVOLD}

Nevrologisk avdeling og Avdeling for forskning og utvikling (Nevroklinikken)

Oslo universitetssykehus

Bendik Slagsvold Winsvold er postdoktor, lege i spesialisering i nevrologi og forsker ved Nevrologisk avdeling og Forsknings- og utviklingsavdelingen, Nevroklinikken, Oslo universitetssykehus.

Forfatteren har fylt ut ICMJE-skjemaet og oppgir følgende interessekonflikt: Han har mottatt foredragshonorarer fra Novartis. 
Nevrologisk avdeling og Helsetjenesteforskning (HØKH)

Akershus universitetssykehus

Christofer Lundqvist er overlege ved Nevroklinikken, Akershus universitetssykehus, og professor II ved Universitetet i Oslo.

Forfatteren har fylt ut ICMJE-skjemaet og oppgir følgende interessekonflikter: Han har mottatt honorarer fra Abbvie og Roche.

\section{STÅLE O. SAGABRÅTEN}

Nesbyen legesenter

Ståle O. Sagabråten er spesialist i allmennmedisin og fastlege ved Nesbyen legesenter. Han er nestleder i Norsk forening for allmennmedisin.

Forfatteren har fylt ut ICMJE-skjemaet og oppgir ingen interessekonflikter.

Anne Hege Aamodt har invitert alle forfatterne, og de har i fellesskap kommet med innspill til innhold og bestemt avgrensningen av artikkelen. Aamodt har utarbeidet manuskriptet, og alle medforfatterne har gått gjennom det flere ganger og godkjent siste versjon.

Korrekt diagnostikk av ulike hodepinetyper kan være utfordrende, men det er den viktigste forutsetningen for optimal behandling. Det anbefales kontrollert bruk av anfallsmedisin og forebyggende tiltak.

Hodepinesykdommer er ifølge sykdomsbyrdeprosjektet Global Burden of Disease blant de vanligste årsakene til funksjonsnedsettelse (1). Lidelsene påvirker i stor grad samfunnet, personene som rammes og de pårørende. Enkle diagnostiske verktøy og terapeutiske tiltak kan utgjøre en stor forskjell. Formålet med denne artikkelen er å gi konkrete råd for diagnostikk, behandling og oppfølging av hodepinepasienter. Vi vil også omtale noen nye behandlingsmuligheter.

Artikkelen er basert på litteratursøk i PubMed, egne kliniske erfaringer og NevroNEL (2).

\section{Migrene}

\section{FOREKOMST OG DIAGNOSTIKK}

Migrene er den vanligste årsaken til at pasienter oppsøker lege på grunn av primær hodepine. Forekomst av migrene i Norge er $8 \%$ hos barn, $6 \%$ hos menn og $18 \%$ hos kvinner (3). Et enkelt verktøy som «ID migraine» (tre korte spørsmål om lysskyhet, funksjonsnivå og kvalme under hodepineanfall) hjelper med å identifisere migrene (4) (ramme 1). Ved positivt svar på to av de tre spørsmålene er migrene overveiende sannsynlig. For å få bedre oversikt over omfanget av hodepineplagene, kan åtte utdypende spørsmål gi en god og rask oversikt både for migrene og andre hodepinetyper (ramme 1). Diagnosen migrene uten aura stilles ved minst fem hodepineanfall som varer i 4-72 timer og har minst to av fire typiske karakteristika: ensidige smerter, moderat til alvorlig intensitet, pulserende karakter og forverring ved bevegelse. Dessuten skal minst ett av to tilleggskriterier være oppfylt: kvalme eller lyd- og lysskyhet. Migrene behøver ikke være ensidig, rundt $40 \%$ har dobbeltsidig hodepine. Nakkesmerter er vanlig og forekommer ofte som en del av migreneanfallet $(5,6)$.

\section{Ramme 1 Sentrale spørsmål ved diagnostikk av migrene og andre typer}

\section{hodepiner}

\section{TRE KORTE SPØRSMÅL OM MIGRENE}

P - photophobia: Er du lyssky når du har hodepine?

I - indisposed: Har hodepinen ført til at du har vært borte fra jobb eller fungert dårlig minst

én dag siste tre måneder?

$\mathrm{N}$ - nausea: Blir du kvalm når du har hodepine? 
Har du én eller flere typer hodepine? Beskriv dem hver for seg. Hvor lenge varer hodepinen? (Sekunder, minutter, timer, dager.)

Hvor ofte har du hodepine?

Hvor kraftig er smerteintensiteten?

Hva gjør du under anfall?

Hvor i hodet har du vondt?

Har du ledsagende symptomer?

Tar du medisiner?

Ved migrene med aura innledes hodepinen av ett eller flere forbigående aurasymptomer. Den vanligste auraformen er synsforstyrrelser, men også sensoriske forstyrrelser og tale- og språkforstyrrelser forekommer. Noen pasienter får også lammelser eller symptomer fra hjernestammen som vertigo og dobbeltsyn. I motsetning til slagsymptomer utvikler aurasymptomene seg over minst 5 minutter og kommer gradvis etter hverandre med typisk varighet på 5-6o minutter før hodepinen inntrer. Aurasymptomene arter seg oftest som flimring, lysblink eller prikkinger i huden (6).

\section{BEHANDLING}

Anfallsmedikamenter (analgetika, triptaner) og eventuelt antiemetika bør tas så tidlig som mulig ved migreneanfall, fordi det gir best effekt (5). Mange flere migrenepasienter bør sannsynligvis teste ut forebyggende behandling, og ved hyppige anfall kan tidlig start av forebyggende behandling hindre utvikling av daglig hodepine (kronifisering) (2). Terskelen for å starte forebyggende medikamentell behandling er individuell, men bør vurderes allerede ved to-tre migreneanfall per måned, ved liten effekt eller uttalte bivirkninger av anfallsbehandling, eller ved invalidiserende aurasymptomer (2). Betablokker og/eller angiotensin II-reseptorblokker bør være testet ut i adekvat dose og tid hos fastlege før henvisning til nevrolog. Andre alternativer er trisykliske antidepressiver som amitriptylin og antiepileptika som topiramat og valproat (5). Vi anbefaler at hvert medikament prøves ut over minst tre måneder. Behandlingen tilpasses individuelt ut fra medikamentenes bivirknings-/virkningsprofil og eventuelle andre helseproblemer som medikamentet også kan ha gunstig effekt på. (5). God pasientinformasjon er svært viktig. Forbyggende behandling kan redusere anfallshyppighet og smerteintensitet, og gi bedre effekt av anfallsmedikamenter, men svært sjelden gjøre pasientene helt hodepinefrie. Det kan ta opptil tre måneder før effekt inntrer, og det er viktig at pasientene informeres om dette ved oppstart av behandling. Langsom opptrapping er nødvendig for å redusere risikoen for bivirkninger. Det anbefales å bruke hodepinedagbok for å evaluere effekten.

Spesifikke råd om ikke-medikamentelle tiltak kan gi bedre anfallskontroll. Trening, kosthold, normalisering av vekt og jevnt søvnmønster, med verken for lite eller for mye søvn kan bedre hodepineplagene. Stressmestring med ulike typer avspenningstrening og kognitiv adferdsterapi kan være nyttig.

Forebyggende medikamenter seponeres før planlagt graviditet (2). Kvinner som står på forebyggende medikamentell migrenebehandling når de får bekreftet graviditet, anbefales å seponere medikamentet. Mange blir bedre under svangerskapet (2). Dersom det er hyppige anfall til tross for ikke-medikamentelle forebyggende tiltak, er propranolol førstevalg som forebyggende medikamentell behandling (7). Amitriptylin og verapamil kan eventuelt også vurderes (7).

\section{KRONISK MIGRENE}

Kronisk migrene forekommer hos o,5-1,0 \% av befolkningen og defineres som hodepine som forekommer flere enn 14 dager i måneden over 3 måneder, hvorav minst 8 dager per måned skal være med migrene (6). Det betyr at selv om pasienten kan ha flere dager med hodepine av spenningstype enn migrene, skal diagnosen kronisk migrene brukes dersom det er minst 
åtte migrenedager månedlig. Forebyggende medikamentell behandling er i hovedsak lik som ved episodisk migrene (5). Topiramat $100 \mathrm{mg}$ daglig har best dokumentert effekt (2). Det er også god dokumentasjon for effekt av botulinumtoksin A-injeksjoner gjentatt hver tolvte uke (5). Behandlingene har en betydelig andel av non-respondere og bør avsluttes dersom effekten uteblir. Oksipitalnerveblokade gitt en gang per uke i fire uker etterfulgt av en dose en måned senere har mulig effekt ved kronisk migrene (8). Det er flere nye behandlingsformer ved migrene, blant annet antistoffer mot nevropeptidet kalsitoningenrelatert peptid (CGRP) som er involvert i patofysiologien ved migrene (9). Kronisk migrene forekommer med og uten medikamentoverforbrukshodepine. Dersom pasienten bruker flere smertestillende medikamenter, kan det totale medikamentforbruket $ø$ ke. Hodepineplagene kan da paradoksalt nok bli verre. Vi anbefaler at fastlege prøver ut forebyggende medikamenter over minst tre måneder før henvisning til spesialist.

\section{Hodepine av spenningstype}

Omkring $30 \%$ av den voksne befolkningen har flere månedlige anfall med hodepine av spenningstype (2). 2-3\% av befolkningen har kronisk hodepine av spenningstype med over 14 hodepinedager i måneden (2). Kvinner rammes oftere enn menn. Hodepine av spenningstype karakteriseres ved pressende/strammende, dobbeltsidig smerte av mild til moderat styrke, uten forverring ved fysisk aktivitet. Kvalme og oppkast passer ikke med diagnosen, men enten lys- eller lydskyhet kan være til stede (6).

Ikke-medikamentell forebyggende behandling står sentralt, og anbefalingene er i stor grad de samme som ved migrene. Det er viktig å identifisere utløsende faktorer og vurdere sammenhengen mellom psykiske påkjenninger og fysiske plager (2).Ved episodisk hodepine av spenningstype holder det med anfallskuperende medikamentell behandling med analgetika, men ved hyppig eller kronisk hodepine av spenningstype bør profylaktisk behandling benyttes. Analgetika har ofte liten effekt hos pasienter med kronisk hodepine av spenningstype, og øker risikoen for medikamentoverforbrukshodepine. Amitriptylin er førstevalget som forebyggende behandling, mens mirtazapin og venlafaksin er andrevalg og kan forsøkes ved komorbiditet med angst og depresjon (10). Effekt kan vurderes etter to-tre måneder. Også her er pasientinformasjon viktig, ikke minst bør man informere om at medisinen brukes mot hodepine og ikke som antidepressiv. Vi anbefaler at denne typen behandling startes i allmennpraksis, og at seponering forsøkes etter seks måneder for å vurdere om det fortsatt er behov for medisinering. Vi fraråder bruk av diagnosen «hodepine av spenningstype» på pasienter med hodepine man ikke finner ut av, som er anspente i skuldrene eller som har psykososiale problemer uten å oppfylle kriteriene for hodepine av spenningstype. Disse pasientene bør utredes nærmere og henvises til spesialisthelsetjenesten.

\section{Medikamentoverforbrukshodepine}

Alle med hodepine kan utvikle medikamentoverforbrukshodepine dersom de bruker smertestillende medikamenter for ofte. Hodepinen ved medikamentoverforbrukshodepine forekommer i gjennomsnitt flere enn 14 dager per måned og utvikles som en konsekvens av et overforbruk av medikamenter over mer enn 3 måneder (6). Forekomsten av medikamentoverforbrukshodepine er 1-2 \% hos voksne og ca. 0,5\% hos ungdom $(2,3)$. Bruk av opioider, triptaner eller kombinasjonsanalgetika (også kombinasjon med koffein) minst 10 dager per måned i 3 måneder, eller bruk av enkle analgetika minst 15 dager per måned $\mathrm{i}$ 3 måneder, øker risikoen for utvikling av kronisk daglig hodepine (11).

Når man skal vurdere medisinbruk, er det viktig å huske på at mange hodepinepasienter bruker reseptfrie medisiner sammen med medisiner foreskrevet av lege. Fullstendig seponering av anfallsmedikamenter kan være mer effektivt enn inntak av anfallsmedikamenter et par ganger i uken (12). Medikamentavvenningen kan ofte gjennomføres i allmennpraksis om god informasjon og oppfølging gis (11). Vi anbefaler at 
særlig kompliserte tilfeller med tidligere mislykkede avvenningsforsøk eller betydelig komorbiditet håndteres i spesialisthelsetjenesten. Innleggelse kan bli aktuelt, eksempelvis ved alvorlige seponeringssymptomer, tidligere gjentatte mislykkede behandlingsfors $\varnothing \mathrm{k}$ eller markant overforbruk av opioider eller benzodiazepiner. Vi anbefaler bruk av hodepinedagbok, slik at både pasient og behandler kan registrere bedring, og at underliggende hodepinetype lettere kan diagnostiseres. Den beste måten å forebygge medikamentoverforbrukshodepine på er å gi god informasjon når man skriver ut smertestillende. Endring av administrasjonsform eller valg av annen type anfallsmedisin kan for mange også gi bedre anfallskontroll. En annen potensiell årsak til at pasienter utvikler overforbrukshodepine, er at forebyggende behandling igangsettes for sent eller ikke har effekt.

\section{Andre hodepineformer}

Ved hyperakutt, førstegangs intens hodepine må pasienten innlegges akutt for å utelukke subaraknoidalblødning. Pasienter med svært intense hodepineanfall av kort varighet samt pasienter med behandlingsresistente eller atypiske kraniale nevralgier, klasehodepine og andre trigeminale autonome hodepiner bør vurderes av nevrolog. Pasienter med kronisk hodepine av uklar årsak bør også henvises til nevrolog for vurdering. Hemicrania continua og kronisk paroksysmal hemikrani er eksempler på sjeldne hodepiner som responderer på testbehandling med indometacin, og som kan behandles dersom de diagnostiseres.

Nye behandlingsmuligheter for klasehodepine er under utvikling (13). Pasienter med hyppig eller kronisk klasehodepine som ikke har vært fulgt av nevrolog på en stund, vil kunne ha nytte av ny vurdering. Anfallsbehandling er primært sumatriptan-injeksjoner og oksygenbehandling (2). En klaseperiode kan avbrytes med prednisolon, og blokader av nervus occipitalis major kan brukes som overgangsbehandling (2). Forebyggende behandling bør gis ved hyppige klaseperioder (2). Verapamil har best dokumentert effekt, andre alternativer er litium og topiramat (2). Ved kronisk og hyppig episodisk klasehodepine kan stimulatorbehandling mot ganglion sphenopalatinum være aktuelt (13). Resultatene fra den første randomiserte kontrollerte studien viser at $60 \%$ har vedvarende bedring (13). Om lag 20 norske pasienter er behandlet i Danmark (Rigmor Jensen, Dansk Hovedpinecenter, personlig meddelelse). I Norge er dessuten behandling med botulinumtoksin-injeksjoner direkte i ganglion sphenopalatinum under utvikling. Dette kan være et behandlingsalternativ ved kronisk migrene, kronisk klasehodepine og trolig flere typer kronisk hodepine (14).

\section{Veien videre}

Enkel tilnærming med diagnostikk og behandling av migrene, medikamentoverforbrukshodepine og hodepine av spenningstype er meget effektivt. Hodepinediagnostikk er i hovedsak basert på pasientens anamnese. Tidlig oppstart av forebyggende behandling kan hindre kronifisering. Gode råd og pasientinformasjon er tilgjengelig på NevroNEL (2). Hyppig og behandlingsresistent hodepine samt kraftig hodepine med kort anfallsvarighet bør vurderes av nevrolog. Internasjonale studier viser at mange refraktære hodepiner kan behandles effektivt i tverrfaglige spesialiserte hodepinepoliklinikker (15). Vi mener slike bør etableres også i Norge.

\footnotetext{
LITTERATUR:

1. GBD 2015 Neurological Disorders Collaborator Group. Global, regional, and national burden of neurological disorders during 1990-2015: a systematic analysis for the Global Burden of Disease Study 2015. Lancet Neurol 2017; 16: 877-97. [PubMed][CrossRef]

2. Norsk Elektronisk Legehåndbok. Nevrologi. http://nevro.legehandboka.no/ (11.3.2019).

3. Linde M, Stovner LJ, Zwart JA et al. Time trends in the prevalence of headache disorders. The Nord-
} 
Trondelag Health Studies (HUNT 2 and HUNT 3). Cephalalgia 2011;31: 585-96. [PubMed][CrossRef]

4. Lipton RB, Dodick D, Sadovsky R et al. A self-administered screener for migraine in primary care: The ID Migraine validation study. Neurology 2003; 61:375-82. [PubMed][CrossRef]

5. Charles A. Migraine N Engl J Med 2017; 377: 553-61. [PubMed][CrossRef]

6. Headache Classification Committee of the International Headache Society (IHS). The International Classification of Headache Disorders, 3rd edition. Cephalalgia 2018;38:1-211. [PubMed][CrossRef]

7. Burch R. Headache in pregnancy and the puerperium. Neurol Clin 2019;37:31-51.

[PubMed][CrossRef]

8. Sinclair AJ, Sturrock A, Davies B et al. Headache management: pharmacological approaches. Pract Neurol 2015; 15: 411-23. [PubMed][CrossRef]

9. Messina R, Goadsby PJ. CGRP - a target for acute therapy in migraine: Clinical data. Cephalalgia 2019; 39: 420-7. [PubMed][CrossRef]

10. Yu S, Han X. Update of chronic tension-type headache. Curr Pain Headache Rep 2015; 19:469. [PubMed][CrossRef]

11. Alstadhaug KB, Ofte HK, Kristoffersen ES. Preventing and treating medication overuse headache. Pain Rep 2017; 2: e612. [PubMed][CrossRef]

12. Carlsen LN, Munksgaard SB, Jensen RH et al. Complete detoxification is the most effective treatment of medication-overuse headache: A randomized controlled open-label trial. Cephalalgia 2018;38: 225-36. [PubMed][CrossRef]

13. Fontaine D, Santucci S, Lanteri-Minet M. Managing cluster headache with sphenopalatine ganglion stimulation: a review. J Pain Res 2018; 11:375-81. [PubMed][CrossRef]

14. Bratbak DF, Nordgård S, Stovner LJ et al. Pilot study of sphenopalatine injection of onabotulinumtoxinA for the treatment of intractable chronic cluster headache. Cephalalgia 2016;36: 503-9. [PubMed][CrossRef]

15. Steiner TJ, Antonaci F, Jensen R et al. Recommendations for headache service organisation and delivery in Europe. J Headache Pain 2011; 12: 419-26. [PubMed][CrossRef]

Publisert: 3. april 2019. Tidsskr Nor Legeforen. DOI: 10.4045/tidsskr.18.0837

Mottatt 25.10.2018, første revisjon innsendt 9.1.2019, godkjent 20.1.2019.

(C) Tidsskrift for Den norske legeforening 2020. Lastet ned fra tidsskriftet.no 